\title{
Utilizing the QRI as a Diagnostic Assessment and Intervention Instruction: A Case of a Thai Learner
}

\author{
Pragasit Sitthitikul \\ Language Institute, Thammasat University
}

\begin{abstract}
The present exploration aimed to assess a reading level of a young Thai student by using the Qualitative Reading Inventory (QRI), and to plan reading intervention instruction targeted on the identified needs based on the assessment results. In this study, a single case study approach was employed. A seven-year old Thai learner was the focal participant. The research questions are threefold as follows: (1) What was the student's diagnostic assessment result measured by the Qualitative Reading Inventory?, (2) Did the designed QRI-based reading intervention instruction lead to student's literacy growth?, and (3) What was the student' attitude towards the self as a reader, reading, and school before the diagnostic assessment took place, and after the reading intervention? The research instruments used in this study included the QRI tests, semi-structured interviews and observations. The diagnostic assessment results revealed that the student's instructional reading level was at the pre-primer, and the QRI-based intervention instruction proved to assist the student in literacy growth. Moreover, the results from the interviews and observations showed that the student had a better attitude towards reading.
\end{abstract}

Keywords: diagnostic reading assessment; language assessment; second language learners; the Qualitative Reading Inventory; Thai EFL young readers 